\title{
BMJ Open Thyroid disorders and breast cancer risk in Asian population: a nationwide population-based case-control study in Taiwan
}

\author{
Chien-Hsiang Weng, ${ }^{1,2,3}$ Yi-Huei Chen, ${ }^{4}$ Ching-Heng Lin, ${ }^{4}$ Xun Luo, ${ }^{3}$ \\ Tseng-Hsi Lin ${ }^{5,6}$
}

To cite: Weng C-H, Chen Y-H, Lin C-H, et al. Thyroid disorders and breast cancer risk in Asian population: a nationwide population-based case-control study in Taiwan. BMJ Open 2018;8:e020194. doi:10.1136/ bmjopen-2017-020194

- Prepublication history for this paper is available online. To view these files, please visit the journal online (http://dx.doi. org/10.1136/bmjopen-2017020194).

The preliminary results from this study have been presented in part at the 86th Annual Meeting of the American Thyroid Association in Denver, Colorado, USA, by C-HW, 21-25 September 2016.

Received 19 0ctober 2017 Revised 9 January 2018 Accepted 10 January 2018

Check for updates

For numbered affiliations see end of article.

Correspondence to Professor Tseng-Hsi Lin; jth.lin@gmail.com

\section{ABSTRACT}

Objective To evaluate whether hyperthyroidism or hypothyroidism increases the risk of subsequent breast cancer in an Asian population.

Design Nationwide population-based case-control study. Setting All healthcare facilities in Taiwan.

Participants A total of 103466 women (mean age 53.3 years) were enrolled.

Methods 51733 adult women with newly diagnosed primary breast cancer without a previous cancer history between 2006 and 2011 were identified and included in our study. 51733 women with no cancer diagnosis prior to the index date were age matched as controls. Diagnosis of hyperthyroidism or hypothyroidism prior to the diagnosis of breast cancer or the same index date was identified, age, histories of thyroid disease treatment, oestrogen use and radioactive iodine treatment were adjusted.

Main outcome measures To identify risk differences in developing breast cancer among patients with a medical history of hyperthyroidism or hypothyroidism.

Results There was a significantly increased risk of breast cancer in women with hyperthyroidism under the age of 55 years (age <45: OR 1.16, $P=0.049$; age 45-55: OR $1.15, P=0.019)$. Patients with hypothyroidism also showed an increased risk of breast cancer (OR 1.19, $\mathrm{P}=0.029$ ) without statistical significance after stratification by age group (age $<45,45-55,>55$ years). Treatment for thyroid disorders did not alter the association in subgroup analyses ( $P=0.857 ; 0.262$, respectively).

Conclusions Asian women under 55 years of age with history of hyperthyroidism have a significantly increased risk of breast cancer regardless of treatment. Women with history of hypothyroidism may also have an increased risk.

\section{INTRODUCTION}

One in eight women will develop breast cancer in their lifetime, a disease prevalence similar to the risk of thyroid disorders in this population. ${ }^{1-3}$ Since high thyroid hormone levels are found to have oestrogen-like effects in several in vitro studies, thyroid hormone levels and their relation to the development of breast and other cancers have been studied in the past with conflicting results
Strengths and limitations of this study

- This is the first study in an Asian population assessing the association between hyperthyroidism, hypothyroidism, breast cancer and age.

- The main strength of this study is the large population-based dataset which minimised the selection bias.

- The most important limitation of this study is the characteristic of the database. Since it is a National Health Insurance Claims Database, detailed thyroid-stimulating hormone, thyroxine, triiodothyronine level, types and stages of breast cancer are not available for further stratification and analysis.

and primarily in Caucasian populations. Most of the literature published to date have relied on studies of relatively small sample sizes. ${ }^{4-14}$ Sogaard et al published a large study in 2016 using the national registry in Denmark found an increased risk of breast cancer in those who had a medical history of hyperthyroidism without age stratification. ${ }^{5}$

Previous observational studies also showed a higher prevalence of hypothyroidism in patients with breast cancer. ${ }^{15} 16$ Older studies proposed that hypothyroidism may induce the breast epithelial cells' sensitivity to prolactin and oestrogen. ${ }^{17} 18$ A recent systematic review and meta-analysis included 13 population-based studies with a total of 24808 participants through June 2016 found that either hypothyroidism or hyperthyroidism has no related risk for breast cancer. ${ }^{19}$

We conducted the first study in an Asian population in order to assess the association between hyperthyroidism, hypothyroidism and breast cancer in different age groups. It is a nationwide population-based case-control study using the Taiwanese National Health Insurance Research Database (NHIRD), one of the largest administrative healthcare 


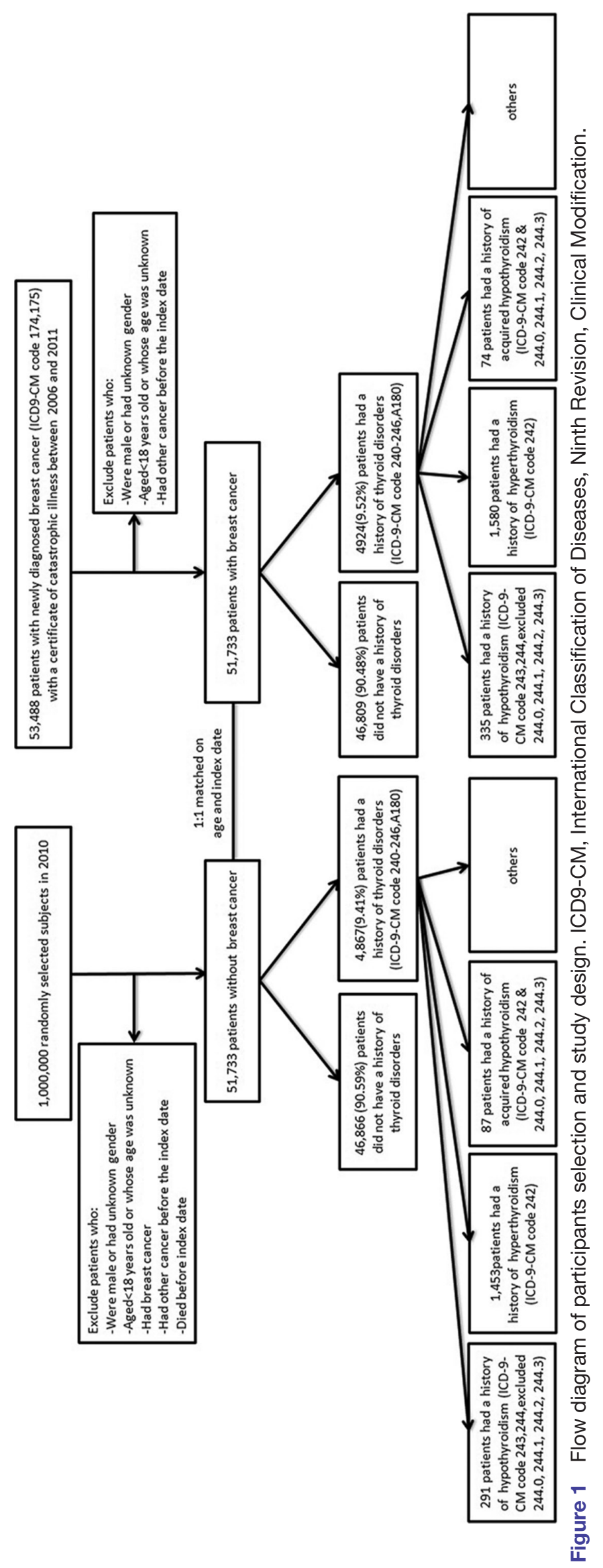

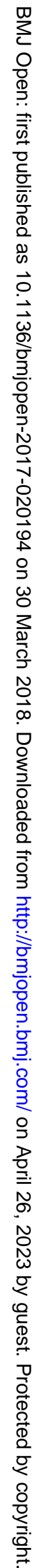


databases in the world; our aim was to discover the relationship between hyperthyroidism or hypothyroidism and breast cancer from the epidemiological aspect.

\section{METHODS}

We designed a case-control study using the Taiwanese NHIRD. Female patients with a new diagnosis of primary breast cancer and no previous cancer history were identified from the NHIRD (diagnosed between 2006 and 2011). Age-matched female individuals without a breast cancer diagnosis were randomly selected as controls. We then identified the status of thyroid disorders prior to the diagnosis of breast cancer in the case group or the same index date in the control group. We excluded those with a history of a thyroid malignancy (figure 1).

\section{Taiwanese NHIRD}

The National Health Insurance programme was established in Taiwan in March 1995 and covers about 99\% of the Taiwanese population. The NHIRD, established by the National Health Research Institute (NHRI), is a claims database maintained by the Department of Health and the NHRI. There are several subset databases in the NHIRD, including the Registry for Catastrophic Illness Patient Database (RCIPD). Breast cancer is defined as a catastrophic illness by the government. Thus, when patients are diagnosed with breast cancer, they will apply and register for the certificate of catastrophic illness.

The Longitudinal Health Insurance Database (LHID) is a database of one million randomly selected insurers from the NHIRD. We used the 2010 version of the LHID which included 1000000 individuals randomly selected from the total of 23251700 insured.

\section{Breast cancer}

In order to identify patients with newly diagnosed primary breast cancer, we searched the NHIRD by using the International Classification of Diseases, Ninth Revision, Clinical Modification (ICD9-CM) code 174 and 175, cross-linking these to the RCIPD. The identified patients all had newly diagnosed breast cancer between 2006 and 2011 and possessed a certificate of catastrophic illness. There were 53488 total patients identified.

We then excluded male gender, age unknown, sex unknown or age $<18$ or $>120$ years old at the time of diagnosis. We excluded patients with diagnoses of other malignant diseases before the diagnosis of breast cancer. A total of 51733 patients were identified from the NHIRD by the above criteria as cases.

\section{Case-control match}

We applied a one-to-one match for the control group, randomly matched for age, sex and the same index date (the month and year of breast cancer diagnosis in the case group) from the LHID. We excluded male gender, age unknown, sex unknown, age $<18$ or $>120$ years old at time of index date or deceased before index date. We excluded patients with the diagnosis of breast cancer. Also, excluded patients were those with diagnoses of other malignant diseases before the index date. A total of 51733 women were selected as controls.

\section{Hyperthyroidism and hypothyroidism}

To identify patients with the diagnosis of hyperthyroidism, we used the ICD9-CM code 242 with additional criteria including the same diagnosis in at least three outpatient visits or one inpatient admission. We stipulated that the first diagnosis of hyperthyroidism had to occur before the date of first breast cancer diagnosis in the case group or the index date in the control group. We used the ICD9-CM codes 243 and 244 with the same additional criteria to identify patients with hypothyroidism. We also excluded patients with ICD9-CM codes 244.0, 244.1, 244.2, 244.3 in the hypothyroidism group since those are acquired hypothyroidism. We identified a specific group of patients with both hyperthyroidism (ICD9-CM 242) and hypothyroidism diagnoses (ICD9-CM 244.0, 244.1, 244.2, 244.3), which represents acquired hypothyroidism from hyperthyroidism treatments. We excluded those with a diagnosis of thyroid malignancy in our study since strong evidences have shown an increased risk of developing breast cancer among thyroid cancer survivors. ${ }^{20}$

\section{Other adjustments}

We adjusted for oestrogen use or hormone replacement therapy, a history of radioactive iodine treatment, medication or surgical treatment for thyroid disease and age. We identified the use of hyperthyroidism, hypothyroidism medications, oestrogen-containing products including oral forms, injection forms or external-use forms available on the market in Taiwan, and labelled them as everused versus never-used. We did not calculate the length of use in each woman since it is very difficult to know their compliance and effects between different products. We also identified women who have ever received radioactive iodine treatment and adjusted it in our analysis.

\section{Statistical analysis}

To examine the differences in clinical characteristics between breast cancer and control groups, we used the Student's t-test to analyse continuous variables and the $\mathrm{X}^{2}$ test to analyse categorical variables. Conditional logistic regression analysis was applied to examine the effect of thyroid disorders, including hyperthyroidism, hypothyroidism and acquired hypothyroidism, on the risk of developing breast cancer, and controlled for potential confounders. Logistic regression analysis was applied to examine the associations between treatments for hyperthyroidism or hypothyroidism and the risk of developing breast cancer in subgroup analysis. All statistical tests were two sided, conducted at a significance level of 0.05 and reported using P values and/or 95\% CIs. All analyses were performed using SAS V.9.4. 
Table 1 Clinical characteristics of study subjects with and without breast cancer

\begin{tabular}{|c|c|c|c|c|}
\hline & Total $(\mathrm{N}=103466)$ & $\begin{array}{l}\text { Without breast cancer } \\
(\mathrm{N}=51733)\end{array}$ & $\begin{array}{l}\text { With breast cancer } \\
(\mathrm{N}=51733)\end{array}$ & \\
\hline Variable & $\mathrm{n}(\%)$ & n (\%) & n (\%) & $P$ value \\
\hline Age, years $($ mean $\pm S D)$ & $53.3 \pm 12.1$ & $53.3 \pm 12.2$ & $53.4 \pm 12.0$ & $0.137^{*}$ \\
\hline Gender & & & & - \\
\hline Female & $103466(100.0)$ & $51733(100.0)$ & $51733(100.0)$ & \\
\hline Male & $0(0.0)$ & $0(0.0)$ & $0(0.0)$ & \\
\hline Thyroid disorders & & & & 0.022 \\
\hline No & $93675(91.0)$ & $46866(91.0)$ & $46809(90.9)$ & \\
\hline With hypothyroidism & $626(0.6)$ & $291(0.6)$ & $335(0.7)$ & \\
\hline With hyperthyroidism & $3033(2.9)$ & $1453(2.8)$ & $1580(3.1)$ & \\
\hline With acquired hypothyroidism & $161(0.2)$ & $87(0.2)$ & $74(0.1)$ & \\
\hline Others & $5462(5.3)$ & $2782(5.4)$ & $2680(5.2)$ & \\
\hline History of oestrogen use & & & & $<0.001$ \\
\hline No & $62834(60.7)$ & $30197(58.4)$ & $32637(63.1)$ & \\
\hline Yes & $40632(39.3)$ & $21536(41.6)$ & $19096(36.9)$ & \\
\hline History of radioactive iodine treatment & & & & 0.670 \\
\hline No & $103378(99.9)$ & $51691(99.9)$ & $51687(99.9)$ & \\
\hline Yes & $88(0.1)$ & $42(0.1)$ & $46(0.1)$ & \\
\hline Medication treatment for thyroid disorder & & & & 0.510 \\
\hline No & $100569(97.2)$ & $50302(97.2)$ & $50267(97.2)$ & \\
\hline Yes & $2897(2.8)$ & $1431(2.8)$ & $1466(2.8)$ & \\
\hline Thyroidectomy & & & & 0.330 \\
\hline No & 102307 (98.9) & $51137(98.8)$ & $51170(98.9)$ & \\
\hline Yes & $1159(1.1)$ & $596(1.2)$ & $563(1.1)$ & \\
\hline
\end{tabular}

Acquired hypothyroidism, with diagnoses of hyperthyroidism + hypothyroidism.

*Student 's t-test; $X^{2}$ test for all other $P$ values.

\section{RESULTS}

A total of 103466 patients were enrolled in our study, 51733 in each group. As for patient characteristics, the mean ages were 53.4 years and 53.3 years in the breast cancer and control groups, respectively $(\mathrm{P}=0.137)$. In the breast cancer group, $36.9 \%$ of the patients had ever used oestrogen-containing medications; in the control group, $41.6 \%$ of patients had ever used oestrogen-containing medications $(\mathrm{P}<0.001)$. Prior to the time of breast cancer diagnosis or the index date, 46 and 42 women received radioactive iodine treatment in the breast cancer and control groups, respectively $(\mathrm{P}=0.67)$. Significant differences in the proportions of thyroid disorders in the breast cancer group and control group were found $(\mathrm{P}=0.022)$. There were 335 patients $(0.7 \%)$ with hypothyroidism in the breast cancer group and 291 patients $(0.6 \%)$ in the control group. A total of 1580 patients $(3.1 \%)$ had the diagnosis of hyperthyroidism in the breast cancer group and 1453 patients $(2.8 \%)$ in the control group (table 1 ).

Both hyperthyroidism and hypothyroidism were associated with an increased risk of developing breast cancer after adjusting for age, oestrogen-containing medication use and a history of radioactive iodine treatment.
Hyperthyroidism in all age groups showed an overall increased risk by $12 \%$ in breast cancer development (OR $1.12,95 \%$ CI 1.04 to $1.20, \mathrm{P}=0.003$ ), while hypothyroidism in all age groups had a $19 \%$ increased risk (OR 1.19, $95 \%$ CI 1.02 to $1.40, \mathrm{P}=0.029$ ). No significant change in risk was found among those who had acquired hypothyroidism after treatment for hyperthyroidism (OR 0.88, $95 \%$ CI 0.64 to $1.22, \mathrm{P}=0.453$ ).

When we stratified by age group (age $<45$, age $45-55$, age $>55$ years), patients with hyperthyroidism aged 55 or under showed a significantly increased breast cancer risk; this association disappeared in those aged 55 years and older. Among patients aged $<45$ years, there was a $16 \%$ increased risk in breast cancer (OR 1.16, 95\% CI 1.00 to $1.34, \mathrm{P}=0.049)$. In those aged $45-55$ years, there was a $15 \%$ increased risk (OR $1.15,95 \%$ CI 1.02 to 1.29 , $\mathrm{P}=0.019$ ). The increased odds for breast cancer in patients with hypothyroidism did not reach statistical significance among those three age groups (table 2).

In the subgroup analysis, we examined whether medication and/or surgical treatment for hyperthyroidism or hypothyroidism would change the risk of having breast cancer. The analysis showed no statistically significant 
Table 2 Adjusted OR of breast cancer associated with thyroid disorders

\begin{tabular}{lllc}
\hline Variable & \multicolumn{2}{l}{ Adjusted } & \\
OR & $\mathbf{9 5 \%} \mathbf{C l}$ & P value \\
\hline Overall & & & \\
\hline Without thyroid disorders & 1.00 & - & - \\
With hypothyroidism & 1.19 & 1.02 to 1.40 & 0.029 \\
\hline Without thyroid disorders & 1.00 & - & - \\
\hline With hyperthyroidism & 1.12 & 1.04 to 1.20 & 0.003 \\
\hline Without thyroid disorders & 1.00 & - & - \\
With acquired hypothyroidism & 0.88 & 0.64 to 1.22 & 0.453 \\
\hline Without thyroid disorders & 1.00 & - & - \\
\hline Others & 0.99 & 0.94 to 1.05 & 0.806 \\
\hline
\end{tabular}

Age $<45$ years

\begin{tabular}{lllc} 
Without thyroid disorders & 1.00 & - & - \\
With hypothyroidism & 1.07 & 0.71 to 1.60 & 0.757 \\
\hline Without thyroid disorders & 1.00 & - & - \\
With hyperthyroidism & 1.16 & 1.00 to 1.34 & 0.049 \\
\hline Without thyroid disorders & 1.00 & - & - \\
With acquired hypothyroidism & 0.62 & 0.29 to 1.32 & 0.214 \\
\hline Without thyroid disorders & 1.00 & - & - \\
\hline Others & 1.03 & 0.91 to 1.16 & 0.692 \\
\hline Age 45-55 years & & & \\
Without thyroid disorders & 1.00 & - & - \\
\hline With hypothyroidism & 1.18 & 0.90 to 1.54 & 0.226 \\
\hline Without thyroid disorders & 1.00 & - & - \\
With hyperthyroidism & 1.15 & 1.02 to 1.29 & 0.019 \\
\hline Without thyroid disorders & 1.00 & - & - \\
\hline With acquired hypothyroidism & 0.84 & 0.50 to 1.43 & 0.532 \\
\hline Without thyroid disorders & 1.00 & - & - \\
\hline Others & 1.05 & 0.96 to 1.15 & 0.276
\end{tabular}

Age $\geq 56$ years

$\begin{array}{lllc}\text { Without thyroid disorders } & 1.00 & - & - \\ \text { With hypothyroidism } & 1.23 & 0.98 \text { to } 1.54 & 0.070 \\ \text { Without thyroid disorders } & 1.00 & - & - \\ \text { With hyperthyroidism } & 1.05 & 0.93 \text { to } 1.19 & 0.454 \\ \text { Without thyroid disorders } & 1.00 & - & - \\ \text { With acquired hypothyroidism } & 1.07 & 0.65 \text { to } 1.76 & 0.792 \\ \text { Without thyroid disorders } & 1.00 & - & - \\ \text { Others } & 0.92 & 0.84 \text { to } 1.00 & 0.052\end{array}$

Adjusted OR was adjusted for age, oestrogen use and history of iodine treatment by logistic regression analysis.

differences between treatments for hyperthyroidism or hypothyroidism and the risk of developing breast cancer (OR $1.01,95 \%$ CI 0.88 to $1.17, \mathrm{P}=0.857$; OR $0.80,95 \%$ CI 0.54 to $1.18, \mathrm{P}=0.262$, respectively) (table 3 ).

A separate analysis for autoimmune thyroid disease (AITD) to examine the association with breast cancer showed no statistical significance (OR 0.94, 95\% CI 0.68 to $1.29, \mathrm{P}=0.685$ for Hashimoto's disease; OR 1.20, $95 \%$ CI 0.96 to $1.50, \mathrm{P}=0.109$ for Graves' disease). We
Table 3 Subgroup analysis for treatment-adjusted OR of breast cancer associated with thyroid disorders (TD)

\begin{tabular}{|c|c|c|c|}
\hline Variable & $\begin{array}{l}\text { Adjusted } \\
\text { OR }\end{array}$ & $95 \% \mathrm{Cl}$ & $P$ value \\
\hline \multicolumn{4}{|l|}{ Subjects with hypothyroidism } \\
\hline Without TD medications & 1.00 & - & - \\
\hline With TD medications* & 0.80 & 0.54 to 1.18 & 0.262 \\
\hline \multicolumn{4}{|l|}{ Subjects with hyperthyroidism } \\
\hline $\begin{array}{l}\text { Without TD medications } \\
\text { and surgery }\end{array}$ & 1.00 & - & - \\
\hline $\begin{array}{l}\text { With TD medications } † \text { or } \\
\text { surgery } \ddagger\end{array}$ & 1.01 & 0.88 to 1.17 & 0.857 \\
\hline \multicolumn{4}{|c|}{ Subjects with hyperthyroidism } \\
\hline $\begin{array}{l}\text { Without TD medications } \\
\text { and surgery }\end{array}$ & 1.00 & - & - \\
\hline With surgery§ & 0.97 & 0.74 to 1.27 & 0.825 \\
\hline With TD medications & 1.02 & 0.88 to 1.19 & 0.789 \\
\hline
\end{tabular}

Adjusted OR was adjusted for age, oestrogen use and history of lodine treatment by logistic regression analysis.

*Hypothyroidism medication: levothyroxine.

†Hyperthyroidism medications: methimazole, propylthiouracil (did not include radioactive iodine treatment since it was adjusted separately).

‡Surgery: thyroidectomy (partial or total).

§If the patient received both medication and surgical treatment, the patient would be classified as surgical patient in this subgroup.

also performed an additional analysis with the exclusion of those who only had a 'one-time' diagnosis of thyroid disorder during an inpatient admission to eliminate possible inpatient admission bias. In the breast cancer group, there were 22 patients with only one-time hypothyroidism diagnosis and 77 patients with only one-time hyperthyroidism diagnosis out of 335 and 1580 patients, respectively; while in the control group, 17 patients with only one-time hypothyroidism diagnosis out of 291 and 82 patients with only one-time hyperthyroidism diagnosis out of 1453 patients. After excluding those with only one-time diagnosis of hyperthyroidism or hypothyroidism, the results showed similar associations as above. Hyperthyroidism in all age groups showed an overall increased risk by $13 \%$ in breast cancer development (adjusted OR 1.13, $95 \%$ CI 1.05 to $1.21, \mathrm{P}=0.002$ ), while hypothyroidism in all age groups had an 18\% increased risk (adjusted OR 1.18, $95 \%$ CI 1.01 to $1.39, \mathrm{P}=0.043)$.

\section{DISCUSSION}

This is the first study in an Asian population assessing the association between hyperthyroidism, hypothyroidism and breast cancer. Among a total of 103466 women in our study, we found increased risks of developing breast cancer in patients with medical history of either hyperthyroidism or hypothyroidism despite treatment. The association is significant in patients under the age of 55 years old with hyperthyroidism.

Since Beaston first described using thyroid extract to treat metastatic breast cancer in the Lancet in 1896 , 
many studies have investigated the relationship between thyroid hormone and cancers. ${ }^{21}{ }^{22}$ Specific alterations of thyroid hormone receptors (TRs) have been found in different types of carcinomas, including breast cancer, and many studies observed associations between the expression of TRs and the regulation of oncogenes. ${ }^{22-24}$ Several physiological similarities have been discovered between the thyroid gland and mammary gland. For one, both thyroid follicular cells and breast lactating cells store iodine through natrium iodine symporter-mediated iodine uptake..$^{25-28}$ The oxidation of iodine in the alveolar mammary cells uses lactoperoxidase, which is mechanistically similar to peroxidase in thyroid glands. ${ }^{29}$

Several in vitro studies have shown that high levels of thyroid hormones may possess oestrogen-like effects and may promote breast cancer proliferation and angiogenesis. ${ }^{513222430}$ It has also been shown that the activation of TR in mammary glands may induce the differentiation and lobular growth of breast tissues, an effect similar to that seen with oestrogen. ${ }^{22}{ }^{23}$ Active triiodothyronine (T3) has been found to promote breast cancer cell proliferation and to increase the effect of 17beta-oestradiol-mediated cell proliferation in some breast cancer cell lines. ${ }^{13}$ In population-based studies, T3 levels have also been found to have a positive correlation with breast cancer tumour size and the risk of lymph node metastasis. ${ }^{31}$

Hypothyroidism may trigger hypersensitisation of mammary glandular epithelium to oestrogen and prolactin, possibly related to low circulating thyroid hormone, and further lead to mammary dysplasia and neoplasia of the breast. ${ }^{17} 1832$ Previous studies showed a positive correlation between elevated serum prolactin level and an increased risk of breast cancer, ${ }^{33} 34$ while other study also found that mild hyperprolactinaemia did not carry significant health risks, and thus treatment was not required in postmenopausal women. ${ }^{35}$ The existence of a genetic predisposition for hypothyroidism and breast cancer has been hypothesised as well. ${ }^{6} 10$

We did not find a statistically significant association between AITD and breast cancer risk in this study. However, several studies have shown that there may be a possible association between AITD and breast cancer, but controversial in AITD and breast cancer survival. A study by Jiskra et al found a higher prevalence of euthyroid AITD in women with breast cancer and no prognostic impact from AITD on breast cancer survival. ${ }^{36}$

In our study, the significantly increased risk of breast cancer among patients with the diagnosis of hyperthyroidism under 55 years of age is possibly related to higher levels of thyroid hormone in addition to the physiological level of oestrogen. The increased risk drops from $15 \%-16 \%$ to $5 \%$ with no statistical significance in patients with hyperthyroidism $>55$ years of age. This is likely related to the menopausal status of these patients, an indicator of low oestrogen levels. In the further subgroup analysis, we found that hyperthyroidism treatment with medications and/or surgery and thyroid replacement treatment for hypothyroidism did not alter the risk of having breast cancer in the future. While there is a $19 \%$ increased risk of breast cancer in patients with hypothyroidism, the statistical significance disappears when we stratify these patients into the three age groups. Since there were only 335 patients with a diagnosis of hypothyroidism who developed breast cancer, dividing this group into three age cohorts led to a decrease in power. Based on our overall results, however, we can hypothesise that there is no protective effect of hypothyroidism in the development of breast cancer. Interestingly, the use of oestrogen-containing products (which we controlled for) was not a contributing factor to an increased risk of breast cancer in this study.

In 2017, it is estimated that 40610 women may die of breast cancer in the $\mathrm{USA}^{1}$ Current breast cancer screening guidelines published by the US Preventive Services Task Force recommend biennial screening mammography for women at average risk aged 50-74 years. ${ }^{37}$ The American Cancer Society recommends annual screening mammography for women at average risk aged 45-55 years and then biennial screening after 55 years of age. ${ }^{38}$ Our nationwide population-based study showed a significantly increased breast cancer risk in Asian women with medical history of hyperthyroidism under the age of 55 years and an increased risk or at least no protective effect of hypothyroidism. More studies are needed to examine this association in different age groups.

\section{Limitations}

The findings from our study were derived from a large population-based dataset; this minimised selection bias. The case-control study design using an administrative claims database reduced the recall bias; however, the findings might be less accurate due to the lack of supporting laboratory data; this includes thyroid antibody, thyroid-stimulating hormone and thyroid hormones levels as well as breast cancer stages and receptor status. In order to minimise bias, we only studied those with a diagnosis of hyperthyroidism or hypothyroidism who were documented as having these diagnoses in at least three outpatient visits or one inpatient admission. All patients with breast cancer in this study had the diagnosis of breast cancer and possessed the certificate of catastrophic illness. To avoid false claims, the National Health Insurance Bureau randomly samples a fixed percentage of claims from each hospital every year to confirm diagnosis validity, and medical records were independently reviewed by professional experts. Since this study is based on administrative claims, the results may be underestimated or overestimated, as only patients who seek medical attention were evaluated and treated. Since thyroid disorders are often chronic diseases rather than acute onset, we thought that it might not be as useful to adjust the time lapse from the diagnosis of thyroid disorder to breast cancer. 


\section{Conclusion}

Our nationwide Asian population-based study suggests that Asian women under the age of 55 years with medical history of hyperthyroidism have a significantly increased risk of developing breast cancer regardless of treatment. Women with a history of hypothyroidism may also have an increased risk. Further studies are needed to assess the association between age, hypothyroidism and breast cancer risk.

\section{Author affiliations}

${ }^{1}$ Department of Family Medicine, Brown University Warren Alpert Medical School, Providence, Rhode Island, USA

${ }^{2} \mathrm{NH}$ Dartmouth Family Medicine Residency, Concord Hospital, Concord, New Hampshire, USA

${ }^{3}$ Department of Surgery, Johns Hopkins University School of Medicine, Baltimore, Maryland, USA

${ }^{4}$ Department of Medical Research, Taichung Veterans General Hospital, Taichung, Taiwan

${ }^{5}$ Division of Transfusion Medicine, Department of Pathology and Laboratory Medicine, Taichung Veterans General Hospital, Taichung, Taiwan ${ }^{6}$ Department of Internal Medicine, Chung-Shan Medical University Hospital, Taichung, Taiwan

Acknowledgements Special thanks to Professor and Chair Martha A Zeiger, MD, FACS, FACE, Department of Surgery, University of Virginia; Professor Christopher B Umbricht, MD, PhD, Department of Surgery, The Johns Hopkins University School of Medicine, Baltimore, MD; and Dr Erin R Okawa, MD, Boston Children's Hospital Division of Endocrinology, Boston, Massachusetts, for reviewing the manuscript and their comments. Authors thank all the comments and advice from the conference.

Contributors Concept of study: C-HW and T-HL. Study design: C-HW, XL, C-HL and T-HL. Statistical analysis: Y-HC and C-HL. Interpretation of results: C-HW, Y-HC, XL and C-HL. Manuscript writing: C-HW. The other authors provided inputs, expertise and critical review of the manuscript. C-HW and T-HL contributed as co-senior authors to this article.

Funding This research received no specific grant from any funding agency in the public, commercial or not-for-profit sectors.

Disclaimer The interpretation and conclusions contained herein do not represent those of National Health Insurance Administration, Department of Health or National Health Research Institutes.

Competing interests None declared.

Patient consent Not required.

Ethics approval This study has been approved by the Institutional Review Board of Taichung Veterans General Hospital, Taichung, Taiwan (IRB no: CE13151B-3). The study is based in part on data from the National Health Insurance Research Database provided by the Bureau of National Health Insurance, Department of Health and managed by National Health Research Institutes.

Provenance and peer review Not commissioned; externally peer reviewed.

Data sharing statement Extra data are available by emailing the corresponding author (jth.lin@gmail.com).

Open Access This is an Open Access article distributed in accordance with the Creative Commons Attribution Non Commercial (CC BY-NC 4.0) license, which permits others to distribute, remix, adapt, build upon this work non-commercially, and license their derivative works on different terms, provided the original work is properly cited and the use is non-commercial. See: http://creativecommons.org/ licenses/by-nc/4.0/

(C) Article author(s) (or their employer(s) unless otherwise stated in the text of the article) 2018. All rights reserved. No commercial use is permitted unless otherwise expressly granted.

\section{REFERENCES}

1. U.S. breast cancer statistics. 2017. http://www.breastcancer.org/ symptoms/understand_bc/statistics
2. American Thyroid Association. 2017. http://www.thyroid.org/mediamain/about-hypothyroidism/

3. SEER Stat Fact Sheets: Female Breast Cancer, 2017.

4. Khan SR, Chaker L, Ruiter R, et al. Thyroid Function and Cancer Risk: The Rotterdam Study. J Clin Endocrinol Metab 2016;101:5030-6.

5. Søgaard M, Farkas DK, Ehrenstein V, et al. Hypothyroidism and hyperthyroidism and breast cancer risk: a nationwide cohort study. Eur J Endocrinol 2016;174:409-14.

6. Kuijpens JL, Nyklíctek I, Louwman MW, et al. Hypothyroidism might be related to breast cancer in post-menopausal women. Thyroid 2005;15:1253-9.

7. Angelousi AG, Anagnostou VK, Stamatakos MK, et al. Mechanisms in endocrinology: primary HT and risk for breast cancer: a systematic review and meta-analysis. Eur J Endocrinol 2012;166:373-81.

8. Tseng FY, Lin WY, Li Cl, et al. Subclinical hypothyroidism is associated with increased risk for cancer mortality in adult Taiwanese-a 10 years population-based cohort. PLoS One 2015;10:e0122955.

9. Goldman MB, Monson RR, Maloof F. Cancer mortality in women with thyroid disease. Cancer Res 1990;50:2283-9.

10. Smyth PP. The thyroid and breast cancer: a significant association? Ann Med 1997;29:189-91.

11. Morabia A, Szklo M, Stewart W, et al. Thyroid hormones and duration of ovulatory activity in the etiology of breast cancer. Cancer Epidemiol Biomarkers Prev 1992;1:389-93.

12. Tosovic A, Bondeson AG, Bondeson L, et al. Prospectively measured triiodothyronine levels are positively associated with breast cancer risk in postmenopausal women. Breast Cancer Res 2010;12:R33.

13. Hall LC, Salazar EP, Kane SR, et al. Effects of thyroid hormones on human breast cancer cell proliferation. J Steroid Biochem Mol Biol 2008; 109:57-66.

14. Moeller LC, Führer D. Thyroid hormone, thyroid hormone receptors, and cancer: a clinical perspective. Endocr Relat Cancer 2013;20:R19-R29.

15. Smith GL, Smith BD, Giordano SH, et al. Risk of hypothyroidism in older breast cancer patients treated with radiation. Cancer 2008;112:1371-9.

16. Khan NF, Mant D, Carpenter L, et al. Long-term health outcomes in a British cohort of breast, colorectal and prostate cancer survivors: a database study. Br J Cancer 2011;105(Suppl 1):S29-S37.

17. Mittra I. Mammotropic effect of prolactin enhanced by thyroidectomy. Nature 1974:248:525-

18. Vorherr $\mathrm{H}$. Thyroid disease in relation to breast cancer. Klin Wochenschr 1978;56:1139-45.

19. Fang Y, Yao L, Sun J, et al. Does thyroid dysfunction increase the risk of breast cancer? A systematic review and meta-analysis. $J$ Endocrinol Invest 2017;40:1035-47.

20. Kuo JH, Chabot JA, Lee JA. Breast cancer in thyroid cancer survivors: an analysis of the surveillance, epidemiology, and end results-9 database. Surgery 2016;159:23-30.

21. Beatson G. On the treatment of inoperable cases of carcinoma of the mamma: suggestions for a new method of treatment, with illustrative cases. The Lancet 1896;148:162-5.

22. Conde I, Paniagua R, Zamora J, et al. Influence of thyroid hormone receptors on breast cancer cell proliferation. Ann Oncol 2006;17:60-4.

23. González-Sancho JM, García V, Bonilla F, et al. Thyroid hormone receptors/THR genes in human cancer. Cancer Lett 2003;192:121-32.

24. Dinda S, Sanchez A, Moudgil V. Estrogen-like effects of thyroid hormone on the regulation of tumor suppressor proteins, p53 and retinoblastoma, in breast cancer cells. Oncogene 2002;21:761-8.

25. Smyth PP, Shering SG, Kilbane MT, et al. Serum thyroid peroxidase autoantibodies, thyroid volume, and outcome in breast carcinoma. J Clin Endocrinol Metab 1998;83:2711-6.

26. Dai G, Levy O, Carrasco N. Cloning and characterization of the thyroid iodide transporter. Nature 1996;379:458-60.

27. Chung JK. Sodium iodide symporter: its role in nuclear medicine. J Nucl Med 2002;43:1188-200.

28. Turken O, Narln Y, Demlrbas S, et al. Breast cancer in association with thyroid disorders. Breast Cancer Res 2003;5:R110-3.

29. Fierabracci P, Pinchera A, Campani D, et al. Association between breast cancer and autoimmune thyroid disorders: no increase of lymphocytic infiltrates in breast malignant tissues. J Endocrinol Invest 2006;29:248-51.

30. Nogueira CR, Brentani MM. Triiodothyronine mimics the effects of estrogen in breast cancer cell lines. J Steroid Biochem Mol Biol 1996;59:271-9. 
31. Tosovic A, Bondeson AG, Bondeson L, et al. T3 levels in relation to prognostic factors in breast cancer: a population-based prospective cohort study. BMC Cancer 2014;14:536.

32. Kwa HG, van der Gugten AA, Sala M, et al. Effect of pituitary tumours and grafts on plasma prolactin levels. Eur J Cancer 1972;8:39-53.

33. Hankinson SE. Endogenous hormones and risk of breast cancer in postmenopausal women. Breast Dis 2005;24:3-15.

34. Tworoger SS, Hankinson SE. Prolactin and breast cancer risk. Cancer Lett 2006;243:160-9.

35. Schlechte JA. Clinical practice. Prolactinoma. N Engl J Med 2003;349:2035-41.
36. Jiskra J, Barkmanova J, Limanova Z, et al. Thyroid autoimmunity occurs more frequently in women with breast cancer compared to women with colorectal cancer and controls but it has no impact on relapse-free and overall survival. Oncol Rep 2007;18:1603-11.

37. Siu AL. U.S. Preventive Services Task Force. Screening for breast cancer: U.S. Preventive services task force recommendation statement. Ann Intern Med 2016;164:279-96.

38. Oeffinger KC, Fontham ET, Etzioni R, et al. Breast cancer screening for women at average risk: 2015 guideline update from the American cancer society. JAMA 2015;314:1599-614. 